\title{
sciendo
}

\section{The Effects of a 9-Week Hip Focused Weight Training Program on Hip And Knee Kinematics and Kinetics in Experienced Female Dancers}

\author{
by \\ Sandro Rajic ${ }^{1,2}$, Hayley S. Legg'1, Philipp Maurus², Sandro R. Nigg², \\ Daniel J. Cleather ${ }^{1,3}$
}

Increased involvement of the hip musculature during some movements is associated with enhanced performance and reduced injury risk. However, the impact of hip dominant weight training methods on movement strategy has seen limited attention within the literature. The aim of this study was to evaluate if a 9-week hip dominant weight training intervention promotes a more hip dominant movement strategy leading to an improvement in countermovement jump performance. Twenty-two experienced female dancers were recruited and separated into an intervention (age $24.4 \pm 6.3$ years, body height $165.5 \pm 5.8 \mathrm{~cm}$, body mass $65.9 \pm 5.6 \mathrm{~kg}$ ) and a control (age $22.9 \pm 5.6$ years, body height $163.3 \pm 5.4 \mathrm{~cm}$, body mass $57.4 \pm 6.8 \mathrm{~kg}$ ) group. The intervention group participated in a 9-week hip dominant training intervention, which consisted of a wide stance back squat, Romanian deadlift, hip thrusters, and a bent over row. Hip and knee kinematics and kinetics, and countermovement jump performance were assessed pre and post training. Significant interaction effects were found for peak hip joint moment $(p=0.030, \eta 2=0.214)$ and countermovement jump performance $(p=0.003, \eta 2=0.356)$, indicating an increase in peak hip joint moment and countermovement jump performance for the intervention group. Specifically, the intervention group showed a mean increase in jump height of $11.5 \%$. The data show that the use of a hip dominant weight training strategy can improve hip contribution in the propulsion phase of the countermovement jump. Strength and conditioning specialists should incorporate hip dominant weight training exercises to increase hip strength and improve performance.

Key words: hip/knee dominance, vertical jump, movement strategy, strength training, performance, injury prevention.

\section{Introduction}

Dance requires a balance of athletic and aesthetic abilities - the dancer must be able to execute the desired choreography by means of highly challenging, dynamic, and powerful actions, while at the same time making it look effortless and easy (Allen et al., 2012; Angioi et al., 2009). Studies have observed that classical ballet and modern dance are as demanding as many team sports and are highly jump-intensive (Angioi et al., 2009; Liederbach et al., 2004). To prepare for the aforementioned demands and limit injuries, it has been suggested that lower extremity strength and specific muscle contributions are essential for these outcomes (Bennell et al., 1999; Bobbert, van Ingen Schenau, 1988; Malkogergos et al., 2013).

Malkogeorgos et al. (2013) reported that supplemental training had the greatest effect in reducing the incidences of dance-related injuries. In their systematic review on the relationship between muscular strength and dance injuries, Moita et al. (2017) concluded that, although research is still limited, pre-professional dancers who got injured tended to have lower strength

1 - Faculty of Sport, Health and Applied Science, St. Mary's University, Twickenham, London, UK.

2 - Human Performance Laboratory, Faculty of Kinesiology, University of Calgary, Calgary, Alberta, Canada.

3 - Institute for Globally Distributed Open Research and Education (IGDORE). 
values in the lower extremities compared to noninjured dancers. Specifically, a lower recruitment of the gluteal musculature during jumping and landing, may increase the risk of injury in the hip area as well as inhibit performance (Hewett, 2006; Popovich and Kulig, 2012). This is supported by Orishimo et al. (2007) who suggested that the dancer's ability to control the dissipation of the landing forces through the hip, may help them avoid serious lower extremity injuries.

The positive effect of supplemental training programs, such as weight training and plyometric interventions, on jumping performance, movement strategy, and physiological adaptations in dancers is also supported in the literature (Angioi, 2012; Brown et al., 2007). Angioi (2012) found significant improvements in jump height after 6 weeks of supplemental training in dancers. Brown et al. (2007) observed that after a weight training and plyometric intervention was applied to a dance population, aesthetic movement patterns were seen to positively change. Similarly, Brown et al. (2007) showed improvement in jump height, aesthetic performance, and an increase in hamstring strength following a 6-week strength training and plyometric intervention.

When jump mechanics are assessed, a certain pattern in movement strategy appears to be exhibited. Nagano et al. (2005) observed that during a countermovement jump (CMJ), the iliopsoas, rectus femoris, and biceps femoris short head were some of the primary muscles activated in the initial phase. Additionally, the authors found that the gluteus medius, gluteus minimus, adductor longus, and adductor magnus, in addition to the hip external rotators, were the main contributors in the jumping phase. However, it has also been demonstrated that jumpers can exhibit hip or knee dominant (or balanced) strategies (Cleather et al., 2013). Ford et al. (2009) showed that the contribution of the hip joint would appear to be an influential factor in jump performance. The authors showed that better jumpers exhibited larger hip joint moments in the vertical jump. Additionally, Lees et al. (2004) showed that superior vertical jump performance was correlated with increased moments at the hip. These findings are similar to those by Kim and Kim (2011) who showed that as jump height increased, moments at the hip increased more than those of the knee and ankle.

If jumping has an optimal movement strategy, it could be argued that strength training should also follow a similar muscle recruitment and movement strategy for optimal results. A study by Lorenzetti et al. (2012) showed that specificity of joint contribution needs to be applied to effectively target areas of the body that need to be used. The authors showed that flexion at the knee or hip would cause different joint moment contributions at each joint. A larger flexion at the knee will cause a greater joint moment contribution at the knee and lower joint moments at the hip.

Considering that dance is a jumpintensive activity, comprised of dynamic and powerful movements in the vertical and horizontal direction, it is plausible that an appropriately applied supplemental weight training program focused on increasing the coordination and contribution of the musculature around the hip joint, may be highly beneficial for dancers. Therefore, the purpose of this study was to determine the effect of a 9-week hip dominant training strategy on hip and knee kinematics and kinetics in experienced adult dancers. There were two primary hypotheses to this study. First, it was hypothesized that a 9-week hip dominant training program would increase the kinematic (hip joint angular velocities (HJAV)) and kinetic (hip net joint moments (HNJM)) influence of the hip compared to the knee. More specifically, it was hypothesized that greater hip joint moments would be exhibited in the propulsive and landing phases. Secondly, it was hypothesized that there would be a significant improvement in jump height for the intervention group.

\section{Methods}

\section{Participants}

Twenty-two female experienced dancers were recruited to participate in this study. Ten participants (age $=24.4 \pm 6.3$ years, body mass $=$ $65.9 \pm 5.6 \mathrm{~kg}$, body height $=165.5 \pm 5.8 \mathrm{~cm}$ ) were assigned to the intervention group (IG) and twelve participants (age $=22.9 \pm 5.6$ years, body mass $=57.4 \pm 6.8 \mathrm{~kg}$, body height $=163.3 \pm 5.4 \mathrm{~cm}$ ) were included in the control group (CG). There was no difference between the IG and the CG for age or height, but the IG was significantly heavier. A convenience sampling method was chosen due 
to scheduling and availability of participants.

All dancers were currently employed by a professional company, freelance dancers, collegiate level dancers, or recently retired (2 years) from professional dance. All participants were required to have at least eight years of dance experience. All dancers had prior experience in weight training, however, only four of participants had formal training with a personal trainer and/or strength and conditioning coach. Participants in both the control and the intervention group were excluded from the study if they reported injuries limiting them from dancing or were unable to commit to the full 9week intervention. Participants were allowed to miss a maximum of four sessions before being excluded from the study.

Ethical approval was obtained from an Institutional Review Board. All participants completed a medical history questionnaire and signed the necessary informed consent forms. Prior to signing the consent form, each participant was made aware of the risks associated with the study.

\section{Measures}

Thirty-eight reflective markers were placed on each participant as follows: bilaterally on the anterior superior iliac spine (ASIS), posterior superior iliac spine (PSIS), greater trochanter, mid-thigh, medial and lateral knee (joint line), mid shank, medial and lateral ankle (malleolus), posteriorly on the calcaneus, and superiorly on the dorsal aspect of the foot on the $1^{\text {st }}, 2^{\text {nd }}$ and $5^{\text {th }}$ metatarsals (Figure 1). Static (neutral) trials were performed to align the joint coordinate system prior to the jumps, as previously described (Havens and Sigward, 2015).

Kinetic data for the CMJ were measured at $2400 \mathrm{~Hz}$ on two ground-mounted force plates (Model 9286A, Kistler, Winterthur, Switzerland). The kinematic data were collected using a synchronized eight camera motion analysis system (Motion Analysis Corporation, Santa Rosa, CA, USA) with a sampling rate of $240 \mathrm{~Hz}$. Visual 3D software was utilized for raw data processing and to calculate segmental kinematics and kinetics (version 6: C-Motion, Inc., Germantown, MD, USA). Data obtained from Visual 3D were exported and analyzed using Excel Version 15.28 (Build 161115).

All kinetic data were normalized to body weight and mass. Joint angles were calculated based upon a Cardan angle order of rotation (X: sagittal plane, Y: frontal plane, $\mathrm{Z}$ : transverse plane). Inverse dynamics were used to calculate three-dimensional net joint moments (NJM). Jump height was calculated using the impulsemomentum relationship (Moir, 2008). A threshold of $20 \mathrm{~N}$ of the vertical forces was used to determine the take-off (Kristianslund et al., 2012). The highest jump of each participant was selected for further analysis. Peak propulsive and landing moments were defined as the first substantial peak prior to the take-off and first substantial peak on ground contact (Besier et al., 2007).

\section{Design and Procedures}

Both the pre-testing and post-testing were performed within three days of the start and finish of the 9-week intervention. Each participant's anthropometric data were recorded directly prior to their testing session.

The countermovement jump (CMJ) task was performed to assess the kinematics and kinetics of the hip and knee in the sagittal plane. Participants were instructed to place their hands on their hips for the entirety of the jump. A total of four maximal effort jumps had to be successfully completed. Between jumps, a rest interval of $30 \mathrm{~s}$ was provided.

The training program used in this study was split into three parts, which are explained in further detail below. The exercise intervention was supervised and coached by the first author, who has coached Olympic and professional athletes and has over 10 years of experience in strength and conditioning. The coach provided instructions and guidance to participants to ensure all exercises were performed in a safe and effective manner. The exercises that were used consisted of a) a wide stance back squat (WSBS), b) a hip thrust (HT), c) a Romanian deadlift $(\mathrm{RDL}), \mathrm{d})$ a bent over row (BOR), and e) Nordic hamstring curls (NHCs).

Table 1 shows the structure of each of the three phases. Each training session started with a 5-min general warm-up, which included a light jog, followed by dynamic arm swings and leg swings. After the initial five minutes, participants underwent ten minutes of pre-activation exercises (bird dogs, side planks and glute bridge) and a warm-up at $50-60 \%$ effort and speed. Each training session lasted 45-60 minutes, and 
participants were allowed to use a cool-down of their choice. Video assessment was also completed after each phase and discussed with a medical practitioner to avoid and correct any inherent imbalances.

Phase 1 incorporated a high volume (repetitions) of movement with moderate loads, to better familiarize participants with the exercises and the training protocols. The first session consisted of 8-repetition maximum (RM) testing, which included all of the exercises mentioned above, excluding NHCs.
Phase 2 consisted of weeks 3-5 and began with a 4-RM testing session of all four lifts over the first week. Following this session, participants underwent a more general period where the volume and \% of 4-RM were monitored and prescribed in an individualized linear periodization structure. This phase of the program consisted of lower volume when compared to Phase 1 but of higher load percentages.

\begin{tabular}{|c|c|c|c|c|}
\hline \multicolumn{5}{|c|}{ Table 1} \\
\hline $\begin{array}{l}\text { Phase/ Week } \\
\#\end{array}$ & Session \# & Exercises* & Sets/Reps & $\%$ \\
\hline $1 / 1$ & $\begin{array}{l}1 \\
2\end{array}$ & $\begin{array}{l}\text { WSBS, BOR, HTs, RDL, NHCs } \\
\text { WSBS, BOR }\end{array}$ & $\begin{array}{l}3 \times 10-15 \\
4 \times 8\end{array}$ & $\begin{array}{l}\text { Body mass } \\
\text { 8RM }\end{array}$ \\
\hline & 3 & HTs, RDL & $4 \times 8$ & $8 \mathrm{RM}$ \\
\hline $1 / 2$ & $\begin{array}{l}4 \\
5 \\
6\end{array}$ & $\begin{array}{l}\text { WSBS, HTs, RDL } \\
\text { WSBS, HTs, RDL } \\
\text { WSBS, HTs, RDL }\end{array}$ & $\begin{array}{l}6 \times 6 \\
6 \times 6 \\
6 \times 6\end{array}$ & $\begin{array}{l}50-60 \% \\
50-60 \% \\
50-60 \%\end{array}$ \\
\hline $2 / 1$ & $\begin{array}{l}1 \\
2 \\
3\end{array}$ & $\begin{array}{l}\text { WSBS, BOR } \\
\text { HTs, RDL } \\
\text { WSBS, HTs, RDL, BOR }\end{array}$ & $\begin{array}{l}4 \times 4 \\
4 \times 4 \\
4 \times 4\end{array}$ & $\begin{array}{l}4 \mathrm{RM} \\
4 \mathrm{RM} \\
50-65 \%\end{array}$ \\
\hline $2 / 2$ & $\begin{array}{l}4 \\
5 \\
6\end{array}$ & $\begin{array}{l}\text { WSBS, HTs, BOR } \\
\text { WSBS, HTs, RDL } \\
\text { WSBS, HTs, BOR }\end{array}$ & $\begin{array}{l}4 \times 4 \\
4 \times 4 \\
4 \times 4\end{array}$ & $\begin{array}{l}80 \% \\
82.5 \% \\
85 \%\end{array}$ \\
\hline $2 / 3$ & $\begin{array}{l}7 \\
8\end{array}$ & $\begin{array}{l}\text { WSBS, HTs, RDL, BOR } \\
\text { WSBS, HTs, BOR }\end{array}$ & $\begin{array}{l}4 \times 4 \\
4 \times 4\end{array}$ & $\begin{array}{l}60 \% \\
60 \%\end{array}$ \\
\hline $3 / 1$ & $\begin{array}{l}1 \\
2 \\
3\end{array}$ & $\begin{array}{l}\text { WSBS, HTs, RDL, BOR } \\
\text { WSBS, HTs, RDL, BOR } \\
\text { WSBS, HTs, RDL, BOR }\end{array}$ & $\begin{array}{l}5 \times 2 \\
5 \times 2 \\
5 \times 2\end{array}$ & $\begin{array}{l}85 \% \\
85 \% \\
85 \%\end{array}$ \\
\hline $3 / 2$ & $\begin{array}{l}4 \\
5 \\
6\end{array}$ & $\begin{array}{l}\text { WSBS, HTs, RDL, BOR } \\
\text { WSBS, HTs, RDL, BOR } \\
\text { WSBS, HTs, RDL, BOR }\end{array}$ & $\begin{array}{l}5 \times 2 \\
5 \times 2 \\
5 \times 2\end{array}$ & $\begin{array}{l}90 \% \\
90 \% \\
90 \%\end{array}$ \\
\hline $3 / 3$ & $\begin{array}{l}7 \\
8\end{array}$ & $\begin{array}{l}\text { WSBS, HTs, RDL, BOR } \\
\text { WSBS, HTs, RDL, BOR }\end{array}$ & $\begin{array}{l}5 \times 2 \\
5 \times 2\end{array}$ & $\begin{array}{l}95 \% \\
95 \%\end{array}$ \\
\hline $3 / 4$ & $\begin{array}{l}9 \\
10\end{array}$ & $\begin{array}{l}\text { WSBS, HTs, RDL, BOR } \\
\text { WSBS, HTs, RDL, BOR }\end{array}$ & $\begin{array}{l}5 \times 3 \\
5 \times 3\end{array}$ & $\begin{array}{l}70 \% \\
70 \%\end{array}$ \\
\hline & $\begin{array}{l}\text { BS (wide } \\
\text { anian de }\end{array}$ & $\begin{array}{l}\text { e back squat), BOR (bent ove } \\
\text { NHCs (Nordic hamstring } c\end{array}$ & $\begin{array}{l}\text { s (hip thru } \\
\# \text { (week/ph }\end{array}$ & $\begin{array}{l}\text { RDL } \\
\text { number) }\end{array}$ \\
\hline
\end{tabular}


Table 2

Effects of the 9-week training intervention on hip and knee kinematics and kinetics (control and intervention groups combined).

\begin{tabular}{ccc}
\hline & Pre & Post \\
\hline Jump height $(\mathrm{m})$ & $0.265 \pm 0.039$ & $0.280 \pm 0.037 \dagger$ \\
Propulsive Phase & & \\
KJAV $(\% / \mathrm{s})$ & $-1011.6 \pm 79.5$ & $-1070.2 \pm 95.9 \dagger$ \\
HJAV $(\% / \mathrm{s})$ & $623.9 \pm 93.3$ & $671.8 \pm 93.3 \dagger$ \\
KNJM $(\mathrm{Nm} / \mathrm{kg})$ & $1.33 \pm 0.25$ & $1.41 \pm 0.24 \dagger$ \\
HNJM $(\mathrm{Nm} / \mathrm{kg})$ & $-1.90 \pm 0.43$ & $-1.97 \pm 0.44$ \\
Landing Phase & & \\
KJAV $(\% / \mathrm{s})$ & $671.5 \pm 47.7$ & $683.6 \pm 72.7$ \\
HJAV $(\% / \mathrm{s})$ & $-443.3 \pm 76.1$ & $-509.0 \pm 82.9 \dagger$ \\
KNJM $(\mathrm{Nm} / \mathrm{kg})$ & $1.49 \pm 0.30$ & $1.68 \pm 0.31 \dagger$ \\
HNJM $(\mathrm{Nm} / \mathrm{kg})$ & $-1.67 \pm 0.62$ & $-1.68 \pm 0.41$ \\
\hline
\end{tabular}

All data is mean $\pm S D$

$K J A V=$ knee joint angular velocity; $H J A V=$ hip joint angular velocities;

$H N J M=$ hip net joint moments; KNJM = knee net joint moments

+ Indicates the whole cohort mean significantly different from pre-testing to posttesting $p \leq 0.05$

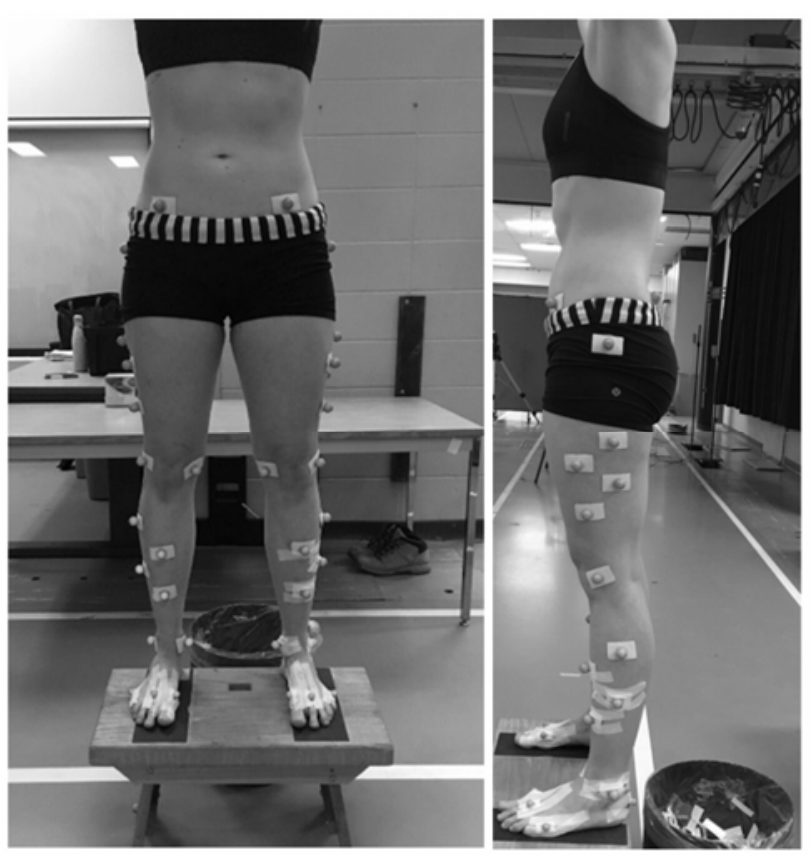

Figure 1

Skin-mounted reflective marker set-up. 


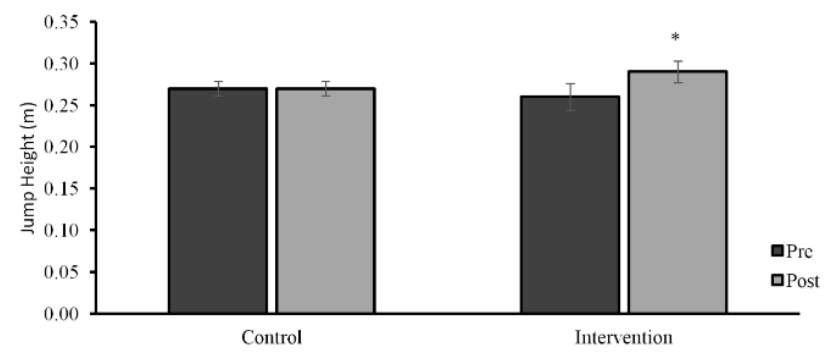

\section{Figure 2}

Pre-testing and post-testing $C M J$ height for control and intervention groups.

Means $( \pm S E)$ for control $(n=12)$ and intervention groups $(n=10)$ indicated above. Asterisk indicates significant difference between pre-testing and post-testing $(p<0.05)$

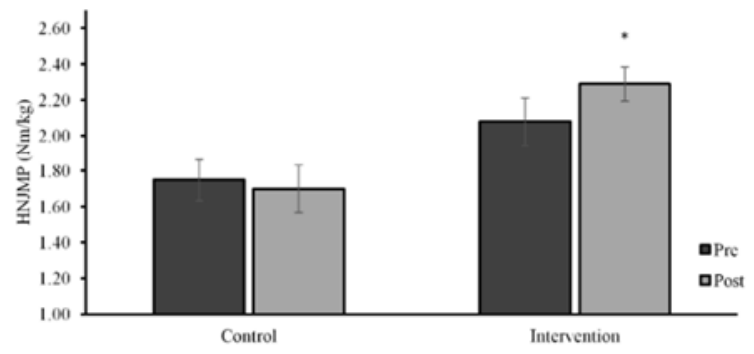

\section{Figure 3}

Pre-testing and post-testing hip net joint moments in the propulsive phase (HNJMP) for control and intervention groups.

Means $( \pm S E)$ for control $(n=12)$ and intervention groups $(n=10)$ indicated above. Asterisk indicates significant difference between pre-testing and posttesting $(p<0.05)$ 
Phase 3 ran during weeks 6-9. This phase utilized the 4RM of the previous phase. However, this was also adjusted by the researcher to account for variability in the participant's day to day life, with an overall increase in the percentage of maximum loads.

\section{Statistical Analysis}

The results were analyzed using IBM SPSS Statistics for Macintosh, Version 24.0 (IBM Crop, Armonk, NY, USA). All data are represented as mean $\pm S D$ s. Four mixed-design two-way repeated measures multivariate analyses of variance (MANOVAs) with Bonferroni corrected post hoc univariate analysis of variance were used to assess the differences between and within groups (CG and IG) and time (pre-test and post-test trials). Separate MANOVAs were used for kinematics and kinetics as well as propulsive and landing phases. Effect sizes were calculated using partial eta squared. The Alpha level threshold was set a priori at 0.05 .

\section{Results}

All participants completed the 9-week training intervention with an overall compliance percentage of $97.5 \%$. Six participants completed 24/24 sessions, two participants completed 23/24 sessions, and two participants completed 22/24 sessions. No major injuries were reported with the exception of a participant who had to miss one session due to illness and one due to a minor injury sustained in dance. Both incidences, however, were limited to one session missed.

There were no significant differences between the IG and the CG during pre-testing in any of the measured performance variables. There was a significant time $\times$ group effect for jump height $\left(p=0.003, \eta^{2}=0.356\right)$ showing that only the IG saw a significant increase (Figure 2). In particular, athletes in the IG improved their jump height by $11.5 \%$. Similarly, there was a time $\times$ group effect for HNJM in favor of the IG that showed significance $\left(p=0.030, \eta^{2}=0.214\right.$; Figure 3).

When the cohort was considered as a whole (time effects only), there were a number of significant changes. During the propulsive phase of the CMJ, there was an increase in HJAV $(p<$ $\left.0.001, \eta^{2}=0.544\right), \operatorname{KJAV}\left(p<0.001, \eta^{2}=0.593\right)$ and $\operatorname{KNJM}\left(p=0.012, \eta^{2}=0.277\right)$ from the pre to post test. Similarly, during landing there were increases in $\operatorname{HJAV}\left(p=0.001, \eta^{2}=0.455\right)$ and KNJM ( $\left.p=0.007, \eta^{2}=0.310\right)$. Jump height also increased from pre to post testing for the whole cohort $\left(p<0.001, \eta^{2}=0.554\right)$. Table 2 shows mean $\pm S D$ descriptive statistics for all kinematic and kinetic variables.

\section{Discussion}

The present study tested the hypothesis that a specifically hip dominant weight training intervention would cause changes in hip and knee mechanics in experienced dancers. It was hypothesized that a larger contribution from the hip (increase in HNJM) would be seen after the intervention and that these changes would lead to superior $\mathrm{CMJ}$ height performance. The findings of this study showed statistically significant changes in HNJM and CMJ height performance during the propulsive phase. However, contrary to the hypothesis no time $\times$ group effects were seen in kinematic and kinetic outcomes for the landing phase.

The IG group significantly increased their jump height from pre-testing to post-testing. This increase in jump height is supported by other research that utilized resistance training methods (Adams et al., 1992; de Villarreal et al., 2011). This improvement in jump height in our study may not be a new finding. However, the level of increase, utilizing only hip dominant weight training, may be worth noting. Our increase of $11.5 \%$ appears to be larger than similar studies conducted to date. In a study that looked at professional futsal players, Paz-Franco et al. (2017) presented an increase of $1.2 \%$ after a 6week resistance program that included a smith machine squat, hamstring curls and leg presses. In their analysis of long-term effects of resistance training, Kavanaugh et al. (2018) found that volleyball players with less than a year of supervised resistance training, improved their jump height by $5.3 \%$ pre-testing to post-testing. Additionally, Contreras et al. (2017) compared front squat and HT effects on the vertical jump and found that hip thrusts had a positive effect on vertical jump performance. However, the change in the vertical jump was of a lower magnitude the authors found an increase of $3.4 \%$ with HT pre-testing to post-testing. Additionally, Carlson et al. (2009) saw a 3.1\% improvement in jump height after a strength training intervention that 
incorporated lower body exercises of the back squat and lunge. Additionally, the authors also found an improvement of $3.1 \%$ following a plyometric only intervention. Our findings appear to be more aligned with the results of training interventions that incorporated more dynamic lifts and plyometric combinations. In a study done by Hoffman et al. (2004) the authors looked at the difference of an Olympic lifting (OL) intervention compared to a traditional lifting (TL) method would have on jump height. The authors found that the OL group saw their jump height increase by $15 \%$, whereas the TL group increased by $1.3 \%$. Additionally, Teo et al. (2016) showed that after an OL intervention and a vertical jump intervention, CMJ improvements were $10.5 \%$ and $6 \%$, respectively. It would appear that traditional resistance training can improve jump height; however, these improvements may be limited when compared to more dynamic and ballistic movements and hip focused weight training interventions.

When observing changes in HNJM, the findings of this study showed a significant increase during the propulsion phase of the CMJ. This is an important finding and suggests that the effect of resistance training is not limited just to improvements in strength, conditioning or hypertrophy. Instead, these results suggest that resistance training can also be used as a modality to promote changes in the movement strategies selected by athletes in general athletic activities. In this study athletes learned to increase the involvement of the hip musculature during vertical jumping, despite the fact that they received no coaching on vertical jump technique during the study. What is unclear from this study is whether this increased involvement was simply due to athletes naturally adopting a movement pattern that allowed them to use their increased strength capacity at the hip, or whether the intervention actually encouraged movement that was more hip dominant (independent of the strength gains). This question should be addressed in future research.

To the authors' knowledge, this is the first study to look at a hip dominant weight training program's effect on NJM and CMJ, thus comparisons between similar research is limited. However, it is worth noting that there are other studies that have established that exercises used in this study do favor a hip dominant movement pattern. Bryanton et al. (2012) showed that during heavy back squats ( $90 \%$ of $1-\mathrm{RM})$, hip to knee ratios increased drastically (1.1:1.0 at $50 \%$ of $1 \mathrm{RM}$ to $1.5: 1.0$ at $90 \%$ of $1-\mathrm{RM})$. The authors observed a $33 \%$ increase of hip extension moment when the squat was performed at $90 \%$ of 1-RM. Additionally, the utilization of a WSBS technique most likely attributed to the strong findings. In a study done by Escamilla et al. (2001) it was shown that wide stance squats compared to narrow stance squats exhibited substantially larger hip extensor moments at the hip. Additionally, Fry et al. (2009) found that when restricting the squat and causing the shins to stay more vertical, larger torques at the hip than at the knee were detected. Furthermore, when HTs were assessed, Contreras et al. (2015) showed that HT produced substantial recruitment of the gluteal musculature. Furthermore, the RDL has been shown to elicit increased hamstrings recruitment (McAllister et al., 2014) which would potentially lead to higher force output around the hip.

It should be noted that there were some time effects in this cohort. In particular, during the propulsive phase there was a small increase in both hip and knee angular velocity and the KNJM for the whole cohort. This suggests that there were some changes in the way in which both CG and IG jumped from pre to post testing, which are most likely to be associated with a familiarization effect. What is most important is that these effects were not statistically significantly different between the two groups, and that the two groups only differed in terms of the increase in jump height and HNJM.

In the assessment of landing mechanics and hip and knee contributions, no time $\times$ group effects were seen in any of the variables. Although the exercises in this study specifically focused on the hip, the landing mechanics did not change. The ability to land may require the athlete to organize their body at a much faster rate, which may rather depend on technical aspects than on strength. This may be supported by Behm and Sale (1993) who showed that amplitude of muscle activation could play an important role in how velocities and moments around a joint contribute to a particular task. The authors state that greater torques would be observed with greater intention of movement. In our study, participants were 
instructed and coached, to control their movement in their exercises on the descent phase to avoid injury. This may have limited the athlete in developing the skills necessary to decelerate the body at a faster rate. Additionally, during CMJ testing, participants were asked to stick their landings, which may have contributed to an earlier deceleration on the landing, causing the knee joint to activate earlier and take a greater load. It could also be proposed that to make changes to landing mechanics, teaching the athlete to specifically think about incorporating a hip dominant movement strategy may be necessary. Oñate et al. (2005) showed that video feedback changed the movement strategies on landing performance, whereas the control group, who had no instruction, did not. Contrary to our hypothesis, a hip dominant training intervention does not facilitate a greater hip contribution in kinetics and kinematics upon landing.

The results of this study suggest that a specific focus on hip dominant weight training exercises can increase HNJM during the propulsion phase and lead to substantial increases in CMJ height. This result is important in demonstrating that resistance training can also result in changes in general movement strategies in movements that are not part of the training program.

\section{Acknowledgements}

SR would like to acknowledge Vivian Rajic, Tyler Shillington, Johan Lahti, Dorian Grenier and Karen Sudds for their continued support during the entire process.

\section{References}

Adams K, O'Shea PJ, O'Shea KL, Climstein, M. The effect of six weeks of squat, plyometric and squatplyometric training on power production. J Appl Sport Sci Res, 1992; 6: 36-41

Allen N, Nevill A, Brooks J, Koutedakis Y, Wyon M. Ballet injuries: Injury incidence and severity over 1 year. J Orthop Sports Phys Ther, 2012; 42: 781-790

Angioi M. Effects of supplemental training on fitness and aesthetic competence parameters in contemporary dance: A randomised controlled trial. Medi Prob Perf Arti, 2012; 27: 3-8

Angioi M, Metsios G, Koutedakis Y, Wyon M. Fitness in contemporary dance: A systematic review. Int J Sports Med, 2009; 30: 475-484

Behm DG, Sale DG. Intended rather than actual movement velocity determines velocity-specific training response. J Appl Phys, 1993; 74: 359-368

Bennell K, Khan KM, Matthews B, De Gruyter M, Cook E, Holzer K, Wark JD. Hip and ankle range of motion and hip muscle strength in young female ballet dancers and controls. Br J Sports Med, 1999; 33: 340-346

Besier TF, Lloyd DG, Cochrane JL, Ackland TR. External loading of the knee joint during running and cutting maneuvers. Med Sci Sports Exerc, 2007; 33: 1168-1175

Bobbert MF, van Ingen Schenau GJ. Coordination in vertical jumping. J Biomech, 1988; 21: 249-262

Brown AC, Wells TJ, Schade ML, Smith DL, Fehling PC. Effects of plyometric training versus traditional weight training on strength, power, and aesthetic jumping ability in female collegiate dancers. J Dance Med Sci, 2007; 11: 38-44

Bryanton MA, Kennedy MD, Carey JP, Chiu LZF. Effect of squat depth and barbell load on relative muscular effort in squatting. J Strength Cond Res, 2012; 26: 2820-2828

Carlson K, Magnusen M, Walters P. Effect of various training modalities on vertical jump. Res Sports Med, 2009; 17: 84-94 
Cleather DJ, Goodwin JE, Bull AMJ. Intersegmental moment analysis characterizes the partial correspondence of jumping and jerking. J Strength Cond Res, 2013; 27: 89-100

Contreras B, Vigotsky AD, Schoenfeld BJ, Beardsley C, Cronin J. A comparison of gluteus maximus, biceps femoris, and vastus lateralis electromyographic activity in the back squat and barbell hip thrust exercises. J Appl Biomech, 2015; 31: 452-458

Contreras B, Vigotsky AD, Schoenfeld BJ, Beardsley C, McMaster DT, Reyneke JHT, Cronin JB. Effects of a six-week hip thrust vs. front squat resistance training program on performance in adolescent males: a randomized controlled trial. J Strength Cond Res, 2017; 31: 999-1008

de Villarreal ESS, Izquierdo M, Gonzalez-Badillo JJ. Enhancing jump performance after combined vs. maximal power, heavy-resistance, and plyometric training alone. J Strength Cond Res, 2011; 25: 32743281

Escamilla RF, Fleisig GS, Zheng N, Lander JE, Barrentine SW, Andrews JR, Bergemann BW, Moorman CT. Effects of technique variations on knee biomechanics during the squat and leg press. Med Sci Sports Exerc, 2001; 33: 1552-1566

Ford KR, Myer GD, Brent JL, Hewett TE. Hip and knee extensor moments predict vertical jump height in adolescent girls. J Strength Cond Res, 2009; 23: 1327-1331

Fry AC, Smith JC, Schilling BK. Effect of knee position on hip and knee torques during the barbell squat. J Strength Cond Res, 2009; 17: 629-633

Havens KL, Sigward SM. Joint and segmental mechanics differ between cutting maneuvers in skilled athletes. Gait Posture, 2015; 41: 33-38

Hewett TE, Myer DG, Ford KR. Anterior cruciate ligament injuries in female athletes: Part 1, mechanisms and risk factors. Amer J Sports Med, 2006; 34: 299-311

Hoffman JR, Cooper J, Wendell M, Kang J. Comparison of Olympic vs. traditional power lifting training programs in football players. J Strength Cond Res, 2004; 18: 129-135

Kavanaugh AA, Mizuguchi S, Sands WA, Ramsey MW, Stone MH. Long-term changes in jump performance and maximum strength in a cohort of national collegiate athletic association division I women's volleyball athletes. J Strength Cond Res, 2018; 32: 66-75

Kim YK, Kim YH. Intersegmental dynamics of the lower limb in vertical jumps. J Mech Sci Technol, 2011; 25: 1817-1822

Kristianslund E, Krosshaug T, van den Bogert A. Effect of low pass filtering on joint moments from inverse dynamics: implications for injury prevention. J Biomech, 2012; 45: 666-671

Lees A, Vanrenterghem J, De Clercq D. The maximal and submaximal vertical jump: Implications for strength and conditioning. J Strength Cond Res, 2004; 18: 787-791

Liederbach M, Dilgen FE, Rose DJ. Incidence of anterior cruciate ligament injuries among elite ballet and modern dancers: A 5-year prospective study. Amer J Sports Med, 2008; 36: 1779-1788

Lorenzetti S, Gülay T, Stoop M, List R, Gerber H, Schellenberg F, Stüssi E. Comparison of the angles and corresponding moments in the knee and hip during restricted and unrestricted squats. J Strength Cond Res, 2012; 26: 2829-2836

Malkogeorgos A, Zaggelidou E, Zaggelidis G, Christos G. Physiological elements required by dancers. Sport Sci Rev, 2013; 22: 343-368

McAllister MJ, Hammond KG, Schilling BK, Ferreria LC, Reed JP, Weiss LW. Muscle activation during various hamstring exercises. J Strength Cond Res, 2014; 28: 1573-1580

Moir GL. Three different methods of calculating vertical jump height from force platform data in men and women. Meas Phys Educ Exerc Sci, 2008; 12: 207-218

Moita JP, Nunes A, Esteves J. The relationship between muscular strength and dance injuries. Med Probl Perform Art, 2017; 32: 40-50 
Nagano A, Komura T, Fukashiro S, Himeno R. Force, work and power output of lower limb muscles during human maximal-effort countermovement jumping. J Electromyogr Kinesiol, 2005; 15: 367-376

Oñate JA, Guskiewicz KM, Marshall SW, Giuliani C, Yu B, Garrett WE. Instruction of jump-landing technique using videotape feedback: Altering lower extremity motion patterns. Amer J Sports Med, 2005; 33: 831-842

Orishimo KF, Kremenic IJ, Pappas E, Hagins M, Liederbach M. Comparison of landing biomechanics between male and female professional dancers. Amer J Sports Med, 2007; 37: 2187-2193

Paz-Franco A, Rey E, Barcala-Furelos R. Effects of 3 different resistance training frequencies on jump, sprint, and repeated sprint ability performances in professional futsal players. J Strength Cond Res, 2017; 31: 3343-3350

Popovich Jr, JM, Kulig K. Lumbopelvic landing kinematics and EMG in women with contrasting hip strength. Med Sci Sports Exerc, 2012; 44: 146-153

Teo SYM, Newton MJ, Newton RU, Dempsey AR, Timothy FJ. Comparing the effectiveness of a short-term vertical jump vs. weightlifting program on athletic power development. J Strength Cond Res, 2016; 30: 2741- 2748

\section{Corresponding author:}

\section{Sandro Rajic, MSc}

216 Elgin Meadows View SE

Calgary, AB T2z 0G1, Canada

Phone: +1-587-894-2263

Email: sandro_rajic@hotmail.com 